\title{
"We found no violation!": Twitter's Violent Threats Policy and Toxicity in Online Discourse
}

\author{
Pooja Casula \\ Georgia Institute of Technology \\ pcasula3@gatech.edu
}

\author{
Aditya Anupam \\ Georgia Institute of Technology \\ aanupam3@gatech.edu
}

\author{
Nassim Parvin \\ Georgia Institute of Technology \\ nassim@gatech.edu
}

\begin{abstract}
Threat moderation on social media has been subject to much public debate and criticism, especially for its broadly permissive approach. In this paper, we focus on Twitter's Violent Threats policy, highlighting its shortcomings by comparing it to linguistic and legal threat assessment frameworks. Specifically, we foreground the importance of accounting for the lived experiences of harassment-how people perceive and react to a tweet-a measure largely disregarded by Twitter's Violent Threats policy but a core part of linguistic and legal threat assessment frameworks. To illustrate this, we examine three tweets by drawing upon these frameworks. These tweets showcase the racist, sexist, and abusive language used in threats towards those who have been marginalized. Through our analysis, we highlight how content moderation policies, despite their stated goal of promoting free speech, in effect, work to inhibit it by fostering an online toxic environment that precipitates self-censorship in fear of violence and retaliation. In doing so, we make a case for technology designers and policy makers working in the sphere of content moderation to craft approaches that incorporate the various nuanced dimensions of threat assessment toward a more inclusive and open environment for online discourse. CONTENT WARNING: This paper contains strong and violent language. Please use discretion when reading, printing, or recommending this paper.
\end{abstract}

\section{CCS CONCEPTS}

- Human-centered computing $\rightarrow$ Collaborative and social computing; Collaborative and social computing theory, concepts and paradigms; Social media; - Social and professional topics $\rightarrow$ Computing/technology policy; Censorship; Hate Speech.

\section{KEYWORDS}

Violent Threats, Online Moderation, Social Media, Free Speech, Twitter, Online Toxicity, Language Analysis, Marginalization

\section{ACM Reference Format:}

Pooja Casula, Aditya Anupam, and Nassim Parvin. 2021. "We found no violation!": Twitter's Violent Threats Policy and Toxicity in Online Discourse. In C\&T '21: Proceedings of the 10th International Conference on Communities \& Technologies - Wicked Problems in the Age of Tech (C\&T'21),

Permission to make digital or hard copies of all or part of this work for personal or classroom use is granted without fee provided that copies are not made or distributed for profit or commercial advantage and that copies bear this notice and the full citation on the first page. Copyrights for components of this work owned by others than ACM must be honored. Abstracting with credit is permitted. To copy otherwise, or republish, to post on servers or to redistribute to lists, requires prior specific permission and/or a fee. Request permissions from permissions@acm.org.

C\&T'21, June 20-25, 2021, Seattle, WA, USA

(C) 2021 Association for Computing Machinery.

ACM ISBN 978-1-4503-9056-9/21/06 . .\$15.00

https://doi.org/10.1145/3461564.3461589
June 20-25, 2021, Seattle, WA, USA. ACM, New York, NY, USA, 9 pages. https://doi.org/10.1145/3461564.3461589

\section{INTRODUCTION}

In 2018, U.S. political analyst and commentator Rochelle Ritchie reported threatening tweets aimed at her, made by an individual named Cesar Sayoc, on Twitter [1]. These tweets, however, were deemed 'non-threatening' by Twitter's Violent Threats policy. Ritchie's report was dismissed, and the tweets remained on the platform. Two weeks later, Cesar Sayoc was arrested for sending pipe bombs to prominent U.S. political leaders, including former President Barack Obama. Twitter apologized to Rochelle Ritchie, stating that the company had made an egregious error in dismissing her report [2, 3].

Rochelle Ritchie's experience with Twitter's limited moderation is, unfortunately, not an anomaly. The company's rationale for this minimal approach to moderation is justified by their goal, "to make Twitter a safe place for free expression” [4], despite many Twitter users' contrary arguments and evidence about how this seemingly inclusive moderation policy has a silencing effect [5]. More specifically, the consequences of Twitter's Violent Threats policy are twofold: one, it negatively impacts how users express themselves or self-censor on the platform, and two, it is commonly referred to as the reason why they leave the platform or decide not to join in the first place [6, 7]. So, we might ask: In what ways does Twitter's Violent Threats policy fall short in identifying and removing violent threats on its platform and what are its consequences?

This paper critically examines Twitter's approach to threats of violence by comparing it to linguistic and legal frameworks of threat assessment. Linguistic analyses of violent and abusive speech have played a major role in developing methods of threat assessment and are key to understanding how Twitter's moderation policy dismisses the presence of linguistic indicators of potential violence. We also draw upon legal frameworks that further build on linguistic approaches, to highlight how the policy is dismissive of threatening speech that could even be subject to prosecution in a U.S. court of law. Together, these two approaches open this research space up to an extensive body of work that helps foreground Twitter's shortcomings as a public social media platform with broader implications for public and civic discourse.

\section{BACKGROUND}

Much of the research on Twitter's content moderation has been centered on hate speech identification and automatic removal. Many studies on hate speech investigate the forms and types of abusive speech that are prevalent on Twitter, their dominant characteristics, as well as the demographics of those who are often the target of such tweets [8-10]. For example, one study found that $89 \%$ of 
the hate speech tweets collected on Twitter targeted individuals based on race, behavioral characteristics ("insecure people", "sensitive people"), and physical traits ("short people”, "obese people") [9]. Another study investigating rape threats on Twitter applied language analysis techniques to tweets to understand the rhetoric surrounding sexual aggression used in online discourse [10]. Such studies have worked to develop an understanding of how online abusive speech is constructed and who are the primary targets of it.

Another area of research in the sphere of content moderation has centered on developing more effective ways of identifying abusive and threatening speech for automatic detection and removal. Many studies focus on how machine learning techniques can be used to conduct automated speech detection [11-13]. The techniques developed in these studies build upon linguistic research for the identification of structure and form of threats to inform automatic classification and identification methods.

These approaches, however, are not without their shortcomings as many scholars have argued. Limitations of algorithmic abusive speech moderation on social media include the inherited bias of machine learning training data and the lack of contextual awareness-both of which disproportionately impact those who have been marginalized. More specifically, algorithmic detection of hate speech both fails to detect toxic speech targeting communities that have been marginalized and blocks non-toxic speech made by members of those communities [14, 15]. For instance, in 2019, Twitter was criticized for blocking a post made by a woman jokingly calling her friend a 'slut'. In a specific context, the word 'slut' is a derogatory slur used against women. However, in this context, the word was being reclaimed by two women who were using the term to jokingly refer to themselves. Twitter's reliance on algorithms to moderate hateful and abusive content was cited as the reason for the obvious lack of attentiveness to context [16].

In response to such criticism, researchers have developed automated systems to flag abusive speech while simultaneously accounting for context. One study suggested quarantining and reviewing tweets that were flagged by automated systems as being potentially abusive. Such a method would ensure that a human reviewer would look over the quarantined tweets and account for the context in which they were made before removing them or making them public [17]. However, the participation of human moderators is only part of the solution given both the ambiguity of policies and the difficulty of tracing the context and relational specificities of conversations online. Indeed, technology policies and guidelines that are used for threat moderation themselves are not without their own flaws. Many studies have shown that reported complaints by those who were threatened on social media are often ignored as they do not exhibit evidence of violating platform-specific threat moderation policies [18-20].

Twitter's Violent Threats policy specifically has received much media and public criticism for its shortcomings. In 2019, Chad Loder, CEO of the cybersecurity company Habitu8, tweeted several screenshots of death threats aimed at U.S. Congresswoman Ilhan Omar that he found doing a simple search on Twitter. Loder criticized the company's inability to remove clear threats targeting the Congresswoman, highlighting the shortcomings of their moderation system to handle the removal of the widespread toxicity that occurs on the platform [21]. In 2020, Omar herself, along with fellow Congresswomen Alexandria Ocasio-Cortez, Ayanna Pressley, and Rashida Tlaib, openly critiqued Twitter's moderation double standard as manifest in their swift action in removing threats made against then-President Donald Trump, while ignoring death threats made against women politicians [22]. Twitter's minimal violent threat moderation has also been critiqued outside of politics. In a tweet thread created by the Director of Cybersecurity of the Electronic Frontier Foundation Eva Galperin, hundreds of Twitter users detailed their experience receiving threats of violence on the platform and the company's inability to remove them [23].

As noted earlier, the failure to address online hate speech negatively impacts the quality and character of online expression. More importantly, inadequate online threat moderation can in effect restrain or impede freedom of expression beyond online spaces. For instance, in 2019, eighteen female members of the UK Parliament decided to not stand for re-election, citing the inordinate amounts of abuse and threats they received online, and the failure to mitigate them, as one of the main reasons [24]. In another case, former U.S. Congressional Candidate Kim Weaver cited that the main reason she ended her campaign for office was the intense amount of online death threats she received during her campaign [25]. Improvements in threat moderation would help alleviate what has been considered a culture of toxicity prevalent on social media broadly, Twitter, specifically.

Research on threat assessment has not directly engaged with the details of Twitter's Violent Threats policy and how its shortcomings can potentially exacerbate online toxicity. We address this gap, in part, by looking into ways that Twitter's Violent Threats policy falls short and what the resulting consequences are. More specifically, we compare and contrast Twitter's threat assessment policy to linguistic and legal methods of identifying threats to highlight the specific limitations in Twitter's threat moderation. We further analyze three tweets drawing upon the linguistic and legal threat identification frameworks to illustrate how Twitter may be turning a blind eye to users who threaten on the platform. In doing so, we aim to present a case for technology designers and policy makers to engage legal and linguistic scholarship when approaching the problem of content moderation more broadly. We conclude by suggesting further directions for analyzing and moderating social media discourses.

\section{SOCIOLINGUISTIC, LEGAL, AND TWITTER'S ANALYSIS OF THREATS}

\subsection{Linguistic Approach}

3.1.1 Linguistic Definitions. The definition of 'threat' has long been a point of philosophic, linguistic, and legal debate. Linguists have generally agreed that threats are "a communication of an intent to harm" [26, 27]. More broadly, drawing upon the work of language philosopher J.L. Austin, a threat can be considered a 'speech act'. Austin argues that there are three acts one could perform when speaking: locutionary acts, perlocutionary acts, and illocutionary acts [28]. Locutionary acts refer to the physical act of speaking. Perlocutionary acts refer to the effect of speech on the audience. Illocutionary acts refer to the act of intention on behalf of the speaker, or as language philosopher Rae Langton elaborates, "the 
action performed simply in saying something" [29]. Many linguists have argued that the speaker's intention, or the illocutionary aspect of speech, is the most important aspect when identifying a threat [27].

However, the emphasis on intent alone has been debated, with scholars arguing that the speaker's intention, or lack thereof, does not determine whether the statement is considered threatening or not. Linguist Kate Storey argues that the context in which a statement is made, and the interpretation of the hearer are necessary when determining whether the said statement is a threat or not [30]. For instance, the phrase "I'm going to find you. .." in the context of a game will be interpreted by the hearer as non-threatening. Yet the same utterance would take on a threatening interpretation if the hearer was being stalked. In both cases, the speaker intends to find the hearer. However, in the latter case, it is presumed that the speaker wants to find the hearer with the further intention of harming them. Here, the context of the statement and the interpretation of the hearer are key aspects in deeming the statement to be a threat.

Sociolinguists have identified three main categories of threats based on their content: direct, conditional, and indirect [31]. Direct threats are specific and typically contain phrases that imply the explicit intent to harm. For example, threats with phrases such as "I will [...]" or "I am planning to [...]" are considered direct due to the use of first-person pronouns and decisive verbs such as 'will' that imply definitive intent [32]. Like direct threats, conditional threats are also specific and contain explicit intent. They follow an 'if-then' format, presenting a condition to the target of the threat directly [33, 34]. An example of a conditional threat would be, "If you don't stop talking right now, I will kill you". Indirect threats, also known as veiled threats, are not specific and typically do not contain any direct intent. This form of threat is highly dependent on context. For example, in many instances of veiled threats, the speaker and target share some degree of knowledge that is unknown to witnesses. In such a case, the speaker ensures that the statement will only be found threatening by the target [35]. Linguist Roger Shuy exemplifies this in the statement, "How's David?" To an outside observer, unaware of the context, this statement appears benign. It appears that the speaker simply wants to know how an individual named David is doing. But in a specific context, in which perhaps David is in danger or missing, the statement shifts from being benign to threatening [36].

3.1.2 Application of Linguistic Definitions. Much research in the area of linguists, especially forensic linguistics, has focused on determining linguistic indicators of potential violence in threats. Researchers have generally found that the more specific a threat is, the more likely it will result in violence. For instance, the statement "I will come to your house with a gun on April 2nd and kill you" is considered more threatening due to its specificity than the statement, "Your time is coming. ..". Common rhetorical features of threats include the use of first-person pronouns ("I", "my"), secondperson pronouns ("you", "your"), obscenities, violent verbs ("kill”, "shoot"), and adverbials of time ("now", "soon") [32]. A study found specific themes based on language in threats that were found to be indicators of violence [37]. Some of these themes were: hopelessness, violent behavior, fantasies, intimidating claims, weapons, deadlines, and racism. When studying and understanding linguistic features of threats, researchers typically focus on direct and conditional threats, as these are most likely to exhibit indicators of individual or collective intent and are therefore the easiest to identify [33].

However, in some instances, conditional threats are confused for warnings. The existence of a conditional clause may serve to warn the recipient of the harmful consequence of not meeting a specified condition. Some sociolinguists have suggested that what distinguishes threats from warnings is when a speaker makes a threat, they control the outcome; yet when a speaker gives a warning, the hearer controls the outcome [39]. Other sociolinguists would argue that in many cases, the line between threats and warnings are purposefully blurred so that those who made the threat can avoid legal consequence $[35,39]$. In such cases, it is the interaction of the intent of the speaker, the context of the situation, and the reaction of the recipient that can clarify whether the statement in question is truly a threat or not.

Indirect or veiled threats are often difficult to identify due to their unpredictable context [33]. With no identifiable structure, it is the very nature of veiled threats that make them more dangerous than direct or conditional threats. Speakers may make veiled threats to create plausible deniability, a situation in which they can reasonably claim that since their statement did not include explicit intent, it should not be considered a threat [45]. For example, consider the phrase "How's the leg?". This phrase could be considered threatening if the speaker hurt the hearer's leg, but to a witness, the phrase would be considered benign. In this case, the speaker could argue that their statement does not implicate themselves as a person who wants to harm the hearer because it contains no direct intention. Since the context of the statement is shared only between the speaker and the recipient, the speaker has created plausible deniability because the only person who would find the statement threatening would be the recipient. This notion that technically any statement, in the right context, can be considered threatening, is also supported by J.L Austin's Speech Act Theory. If the speaker's intention to be threatening was received by the hearer, it can be labeled a threat, regardless of wording [26, 28].

\subsection{Legal Approach}

3.2.1 Legal Definitions. The First Amendment in the U.S. Constitution states that every individual has the right to free speech. Threats of violence are among the few forms of speech that are unprotected by the law [40]. Though the U.S. Supreme Court has yet to take an official stance on what exactly constitutes a threat of violence, they have delineated a set of three criteria, known as the Watts Factors [41], to help distinguish between a threat and a statement protected by the First Amendment. These criteria are very similar to the three components of speech acts outlined by linguists. They include the context of the statement; the conditional nature of the statement (or the intent of the person making the statement); and the reaction of those who hear the statement. The Watts Factors have been influential in guiding the U.S. Courts of Appeals, otherwise known as circuit courts, in their creation of 'True Threat' tests, which have been used as a form of threat identification in court [42]. The U.S. Courts of Appeals comprises a set of 13 appellate courts with each appellate court serving a specific regional district across the United 
States. The U.S. Courts of Appeals are considered the most powerful courts in the U.S., second only to the Supreme Court, and thus have a widespread influence in setting legal precedent and determining policy [43].

Law enforcement agencies draw upon the work of forensic linguists to develop their own set of criteria for distinguishing various forms of threats. According to the Federal Bureau of Investigation (FBI), the principal domestic law enforcement agency of the United States, threats fall under four categories: direct, indirect, veiled, and conditional [44]. The FBI classifies direct threats as those that contain explicit intent to harm a specific individual. For instance, the statement, "I am going to place a bomb in the school's gym" is deemed as a direct threat due to its explicit mention of how the individual intends to harm a group of people. Indirect threats are "vague, unclear, and ambiguous" and imply that a violent act could potentially occur. An example of this can be seen in the statement, "If I wanted to, I could kill everyone here!" The FBI defines a veiled threat as "one that strongly implies but does not explicitly threaten violence", the danger being that the target of the threat is left to think about what might happen. The statement, "We would be better off without you around anymore." does not contain any explicit intent, nor does it implicate the speaker as one to do any harm, yet the recipient of such a statement is left to feel fearful of what could potentially occur to them. Conditional threats are identified as warnings of violence if a demand is not met. For example, "If you don't pay me one million dollars, I will place a bomb in the school" [44].

3.2.2 Application of Legal Definitions. In a U.S. court of law, threats are often distinguished from statements protected by the First Amendment through the use of 'True Threat' tests. There are many different versions of 'True Threat' tests used among different circuit courts, but almost all require evidence of the speaker purposely and knowingly making the statement which tends to be qualified as general intent. Most courts rely upon 'objective' tests, which, in addition to requiring evidence of general intent, emphasize whether a 'reasonable person' would consider the statement in question threatening or not. These 'reasonable person' tests tend to be complicated by whether the court uses the 'reasonable speaker' test or the 'reasonable listener' test. The 'reasonable speaker' test determines the statement to be a threat if the person making the statement anticipates the recipient to interpret it as a threat [42] Thus, "knowingly transmitting the threat makes the act criminal" [46]. The 'reasonable listener' test determines the statement to be a threat if any person, knowing the full context of the statement, finds the statement threatening.

Many free speech activists have argued that the 'reasonable person' tests are not enough for one to be prosecuted as they can lead to many people being punished for simply being careless with their words at a specific moment in time [46]. Several courts approach the 'True Threat' test with a more 'subjective' approach, emphasizing whether the speaker truly had the 'specific intent to threaten' or the 'specific intent to carry out the threat' [42]. While the Supreme Court has yet to determine the specificity of intent required for a threat to be deemed a threat, in all forms of the 'True Threat' tests, the interpretation of the statement by the recipient or a 'reasonable person' listening, is accounted for, in addition to the general intent of the speaker.

In 2015, the U.S. Supreme Court supported the circuit courts' 'reasonable speaker' test in a case involving online threats. In Elonis v. United States [47], the defendant threatened to kill his ex-wife on Facebook. He claimed that he did not intend to kill his ex-wife, but rather was posting angsty rap lyrics to reflect how he felt about their separation. This case echoes the previously mentioned instance of plausible deniability. In this case, Elonis posted threatening statements with little to no direct intent as a way to later deny that he had any intention of committing harm. While the Supreme Court ruled in favor of Elonis, due to an error regarding how the case was presented to the jury, they did make a judgment regarding how online threats should be considered. The majority opinion stated that for a statement to be considered a threat, the speaker needs to have the intent of making the threat and know that what they post will be interpreted as a threat. As historian Angus Johnston succinctly summarized in his analysis of the Supreme Court opinion,

"If you make a threat online, and you know the person who receives it will see it as a threat, you're guilty of violating federal law. It doesn't matter if you claim that it's protected speech, or put a smiley face at the end, or point out later that the threat was really just lyrics from an old Beatles song. If you send a threat and you know it'll be interpreted as a threat, you're guilty. Period." [48]

Supreme Court Justice Samuel Alito, in his concurring opinion in the Elonis v. United States case, stated that statements directly addressed to another individual on the Internet can and will be taken more seriously, specifically because of their context [47]. The very nature of Twitter, and social media in general, encourages sharing one's thoughts to a public audience, not necessarily directly addressing one individual. In this context, users can technically make threats on social media without their targets knowing, by simply not tagging them or not mentioning them [49]. Thus, when a user does make a statement about harming an individual and then mentions that person's account, they are ensuring that the tweet will be seen by the person mentioned. A person will take a threat more seriously if they were specifically intended to see it [47]. For instance, a user who simply tweets about harming a U.S. Congresswoman will have less of an impact than a user who tweets directly at the Congresswoman, because that user is ensuring that she will be notified of the message, implying their intent to threaten.

\section{TWITTER'S VIOLENT THREATS POLICY}

\subsection{Twitter's Definition and Application of the Violent Threats policy}

Twitter's definition of 'violent threat' differs from the linguistic and legal interpretations. According to the company's Violent Threats policy, only tweets with the stated "intention to inflict violence on a specific person or group of people" are considered threats and removed from the platform [38]. For example, "I will kill you" would be considered a direct threat since it includes explicit intent to harm. In contrast, tweets that make "vague or indirect threats", 
are excluded and not actionable under their policy [38]. An example of a tweet containing a vague or indirect threat is, "Your time is coming.... Since the statement has no explicit intent and simply hints at potential harm, it is considered non-threatening by Twitter. Put simply, statements that imply a hypothetical or do not carry a specific degree of certainty, whatever that may be, are not classified as threats by Twitter moderators.

In addition to intent, the policy acknowledges the role of context in the decision to classify a statement as a threat. It states: "We recognize that some people use violent language as part of hyperbolic speech or between friends, so we also allow some forms of violent speech where it's clear that there is no abusive or violent intent". For instance, the statement "I will kill you for sending me spoilers!", made between friends, will not be considered a threat under the policy [38]. The sole focus on context and intent, without the inclusion of the lived experiences of harassment by the recipients of such threats, such as their reaction and interpretation, results in the persistence of many tweets that users legitimately find threatening. The problematic nature of this approach is evident when we consider cases such as that of Rochelle Ritchie, as described in the opening of this paper. Her report of Cesar Sayoc's threatening tweet was dismissed, resulting in serious consequences [2]. In other words, compared to linguistic and legal frameworks of threat assessment, Twitter's Violent Threats policy is quite limited. In the following section, we illustrate the relevance and importance of these frameworks for understanding the shortcomings of Twitter's online threat moderation policy through the examination of three tweets. For this purpose, we have selected three tweets aimed at public figures in the U.S.

Of the three tweets we selected, two were aimed at U.S. Congresswoman Alexandria Ocasio-Cortez and one was aimed at U.S. Congresswoman Ilhan Omar. We chose to find tweets targeting these two Congresswomen for two reasons. First, both Congresswoman Ocasio-Cortez and Congresswoman Omar have a large presence on social media, particularly Twitter [50]. Second, both Congresswomen have publicly discussed the inordinate amount of hateful and abusive speech they receive on Twitter specifically [21, 22]. A study conducted by the Institute of Strategic Dialogue found that among the Congresspeople they studied running for reelection in the 2020 U.S. Congressional elections, Congresswoman Omar and Congresswoman Ocasio-Cortez received the highest amounts of online abuse [51].

The rationale for selecting these tweets is threefold. First, they contain a graphic or specific depiction of violence. Second, all three tweets are directly aimed at the Congresswoman in question since they tagged their account. The first and third tweets were made as a direct reply to the Congresswoman's tweet and as a result, directly tagged her account, ensuring that she would see it. The second tweet, while not a direct reply, also directly tagged the Congresswoman's account. Finally, all three tweets remained publicly available on Twitter for an extended time. Two of the three tweets identified remain on Twitter as of April 26th, 2021. The account that made the third tweet was suspended two months after the tweet was made. As a result, the tweet in question is no longer online. We could not determine whether the tweet had any bearing on the suspension of the account.
Each tweet highlights a different form of threat. The first tweet is an instance of a veiled threat of violence. The second tweet is an instance of a conditional threat with mention of explicit violent behavior, and the third tweet is an instance of a threat of sexual violence. Together, these three tweets are illustrative of the toxic nature of discourse on social media, particularly threats and abuse targeting women and people of color. They highlight how such threats can escape moderation when the broader socio-political, cultural, and historical context of public discourse is not accounted for.

The point of drawing upon linguistic and legal analyses of threatening speech with the following three tweets is not to claim that such a tweet could be contested as a threat of violence in a U.S. court of law. Such a claim is outside the scope of this paper and the authors' expertise. Rather, drawing upon the nuances of other wellestablished bodies of knowledge in identifying threats-such as that of sociolinguistic and legal scholars-could shed light on Twitter's threat moderation limitations. In other words, we draw upon linguistic and legal frameworks to foreground how Twitter's Violent Threats policy fails those who are threatened on the platform.

\subsection{Three Illustrative Tweets}

4.2.1 Tweet \#1. In Tweet\#1 (see Table 1), the user makes a demeaning comment to Congresswoman Ilhan Omar, followed by a veiled reference to killing her: "meet your maker." This tweet contains several linguistic indicators of threatening speech. By directly replying to the Congresswoman, the author of the tweet is directly targeting her. The tweet mentions "you" and "my", words that have been found to be potential indicators of violence as they form a direct connection between the author of the tweet and the recipient of the tweet [37]. It is evident that in this case, the author of the tweet has implicated themselves as an individual who would like for harm to come to the Congresswoman, or more likely, to harm the Congresswoman themselves.

This tweet could also be deemed threatening by legal standards as it could pass a few of the 'True Threat' tests used in circuit courts. While it is difficult to know whether the user had the intention of acting upon their statement or how Congresswoman Omar interpreted the statement, the tweet does contain both general intent and the specific intent to threaten according to the legal standard of the courts. The tweet includes general intent as the user made the deliberate choice to tweet the statement. The tweet also includes the specific intent to threaten, indicated by the fact that the tweet was in direct response to Congresswoman Omar's tweet. This implies that the user ensured that Congresswoman Omar would see the tweet. One may even argue that the general intent and the evidence for the specific intent to threaten implies that the tweet also passes the 'objective' 'reasonable speaker' test [42]. The speaker stated the circumstances in which the Congresswoman would die and then proceeded to directly mention her Twitter account, implying that they had to be reasonably aware that the recipient would find the statement threatening.

We can only speculate regarding why Twitter moderators consider this tweet to not violate their Violent Threats policy. One reason could be that, though this tweet establishes a direct connection between the individual who tweeted and the recipient, the 
Table 1: Tweet\#1 was made on November 10th, 2020 and as of April 26th, 2021, is still publicly available.

\begin{tabular}{ll}
\hline Date & Tweet \\
\hline November 10, 2020 & Replying to @IlhanMN \\
& You are an Almond Joy Candy Bar. \\
& F**KING NUTS. $^{*}$ Knock on my door and meet your maker.
\end{tabular}

Table 2: Tweet \#2 was made on November 7th, 2020 and as of April 26th, 2021, is still publicly available on Twitter.

\begin{tabular}{ll}
\hline Date & Tweet \\
\hline November 7, 2020 & @AOC is calling for punishment Trump, his staffers, supporters \\
& that funded his campaign, etc. They even made their website. \\
& Tyranny. I will personally hunt down AOC and put a bullet in her \\
head if anything comes of this. Idc what your views are, this is & America. We don't do this.
\end{tabular}

tweet lacks explicit intent to harm. The tweet does not contain definitive verbs ("will") or violent verbs \{ "kill”), nor does it contain the use of first-person pronouns ("I"), all common examples of explicit intent. The tweet is quite vague, as the use of the phrase "meet your maker" can be considered an indirect or euphemistic way of saying "to die" [52]. This, coupled with the general absurdity of the tweet may have been considered signs of hyperbolic speech, a form of speech not meant to be taken seriously [53]. However, one cannot dismiss the racist and sexist language of the tweet itself, and how the recipient would reasonably interpret this statement as a threat of harm. This tweet serves as an example of how Twitter may disregard threats that utilize euphemistic language as a mechanism for veiling the violence and therefore evade any consequences under the current platform policies.

4.2.2 Tweet \#2. Tweet\#2 (see Table 2) directly tags Congresswoman Ocasio-Cortez's Twitter account and is making a statement referencing a previous tweet made by the Congresswoman. On November 6th, 2020, Congresswoman Ocasio-Cortez made a tweet about archiving tweets and media made by then-President Donald Trump's supporters who might 'downplay' their 'complicity' in supporting his Presidency [54]. Following this tweet, the Trump Accountability Project, a group created with the purpose of holding then-President Trump and his supporters accountable for their actions, released a statement made on their website. The statement called for people associated with the Trump administration to, in essence, be blacklisted from future job opportunities [55]. The Trump Accountability Project website was later taken down.

This tweet would be characterized as a conditional threat by linguists. Conditional threats typically follow the 'if-then' form, making them quite easy to identify $[33,34]$. While this tweet does not strictly follow the 'if-then' format, it does contain a conditional clause when the author of the tweet states, "I will personally hunt down AOC and put a bullet in her head if anything comes of this", "this" referring to people associated with the Trump administration being potentially blacklisted. The tweet also contains other linguistic features of threats such as the use of personal pronouns, the specific mention of a weapon, the use of words such as "will" which signify intent and action, and the use of the violent verb "hunt" which is often used in the context of chasing to capture or harm $[27,31,56]$.

From a legal standpoint, it may be argued that such a tweet be classified as a threat of violence as it passes several 'True Threat' tests acknowledged by the circuit courts-even though it is difficult to know the Congresswoman's reaction to the tweet or the user's intention to carry out the threat. The tweet includes a general intent as the author of the tweet made the conscious decision to type and post the tweet. It also includes the specific intent to threaten, as the user directly tags the Congresswoman's account to ensure that she views the statement that they made regarding their intention to "hunt" her and shoot her.

While this tweet remains on the platform, it is known that Twitter has flagged tweets with similar statements before, providing evidence that moderators at Twitter consider the mention of a weapon and subsequent violent phrase in this tweet as a threat of violence [57]. Also, regardless of the precedent, the use of the phrase "I will personally hunt down AOC", displays explicit intent, even by Twitter's standard. One can speculate that the reason Twitter has let the tweet remain on the platform is because of its conditional nature. The user claims that if, and seemingly only if, people who are associated with the Trump administration are truly blacklisted, then they will act upon their threat. The 'if' implies a degree of ambiguity and uncertainty and thus moderators may have felt that it need not be acted upon. That being said, the threat made in the tweet is quite direct and explicit, warranting a truly specific and 
Table 3: While Tweet\#3 remained on Twitter until at least December 30th, 2020, this account has been suspended as of April 26th, 2021. It is unknown for what specific reason this account has been suspended.

\begin{tabular}{ll}
\hline Date & Tweet \\
\hline October 29, 2020 & Replying to @AOC \\
& You would look better naked with a bag over your head
\end{tabular}

valid reason from Twitter as to why it has not been taken down yet.

4.2.3 Tweet \#3. Tweet\#3 (see Table 3) was made in response to Congresswoman Ocasio-Cortez's tweet regarding the reaction of many of her colleagues to her appearance on the cover of the wellknown fashion magazine, Vanity Fair [58]. This tweet is arguably referencing both physical and sexual violence against the Congresswoman.

From a sociolinguistic standpoint, such a tweet could be considered a veiled threat. While the user provides a harmful description, they do not implicate themselves as the person doing any harm [26]. Put differently, since the user does not directly say that they will harm the Congresswoman themself, or use personal pronouns, the tweet lacks indicators of direct intent. The tweet also does not use any explicit violent verbs or profanity, other linguistic indicators of threatening violence [32]. However, this tweet does contain themes that some linguists would argue serve as a measure of potential violence [32,37]. The tweet references violent sexual behavior directly targets an individual through the use of second-person pronouns ("you, your head"), and contains a specific method of physical violence (suffocation).

Though this tweet was not flagged by Twitter moderators for an extended time, it does pass a few 'True Threat' tests and could be considered a threat of violence in a U.S. court of law. The tweet contains general intent as the user made the deliberate decision to type out and post the tweet. The tweet also contains the specific intent to threaten as the author uses the word 'you', directly addressing the Congresswoman, in addition to, directly replying to her tweet. The user ensured that she would be able to view their response.

This tweet also passes the 'reasonable speaker' test, as the user had to have known such a tweet would be interpreted as a threat of sexual violence. When the user uses the phrase, 'You would look better naked...', it implies, but arguably does not confirm, that the Congresswoman would look better naked to them specifically. While the user does not use the word "I" or other personal pronouns [31], one can only reasonably assume that the user has made this threat implying that they are the person who intends to attack the Congresswoman and place a bag over her head. Even if this is not the case, the tweet can also serve to instigate others who have viewed this tweet to potentially act on its threat. It is also easy to imagine that anyone on the receiving end of such a statement would reasonably interpret it as a threatening remark.

One can speculate that the main reason why this statement did not violate Twitter's Violent Threats policy is that it did not contain explicit intent. Since the user did not implicate themselves as a person doing any harm, and simply hinted at the potential of harm, the tweet technically did not violate the policy. If this is indeed the case, this tweet serves as an example of how, by only looking for intent words and phrases in tweets, Twitter's Violent Threats policy can fail to consider how one may have interpreted such a graphic and explicit statement. In this case, the policy gives a clear pass to users who are able to make an indirect threat by circumventing Twitter's focus on identifying words and phrases featuring direct intent.

Together, the above tweets illustrate that incorporating context, intent, and interpretation when determining a tweet violation would serve as a good first step for Twitter to create a more inclusive, inviting online environment that does not leave a victim of a threat powerless in the face of the abuser.

\section{DISCUSSION}

The failure of Twitter's threat moderation policy to mitigate threats against powerful politicians is indicative of the broader failure to address violent threats toward public figures and the general public. On the surface, this might seem like an effort to protect free speech, as indicated by the stated goal of the platform [4, 59]. However, free speech is also contingent upon a robust and reliable approach to regulating violent speech if we were to address various forms of self-censorship in fear of violence and retaliation.

That is not to say that content moderation is an easy task. On the contrary, it is a particularly nuanced and difficult practice. The problem of content moderation reflects the broader characteristics of problematic ethical situations, inclusive of the uncertainty that permeates such situations [60]. Linguistic and legal frameworks of threat assessment offer valuable insights into the moderation of online violent threats, especially in their inclusion of how a threat is perceived and experienced, as illustrated in this paper. However, analyzing a tweet for expressions of violence cannot be limited to a focus on linguistic indicators or the application of a set of rules no matter how complex. Rather, content moderation entails accounting for all the different qualities of a rhetorical situation. This includes not only the specific lived experiences and reactions of individuals who are the targets of threats but also the interpersonal, social, political, and historical dynamics and trajectories embodied in the situation. For example, Tweet \#3, "You would look better naked with a bag over your head" is undeniably an expression of violence not only because of linguistic indicators but also because it echoes violent histories of misogyny and racism that all too often mark violent threats against women of color. The tweet can be considered not only an isolated threat to an isolated person but also, a threat to free and democratic discourse as it embodies expressions that have historically been used to silence and disparage women and 
people of color. To overlook the necessity to remove such a tweet under the guise of freedom of speech is to overlook and validate troubling historical trajectories and patterns of behavior complicit in the collective harassment and silencing of voices that have been marginalized.

So, the question remains: whose free speech is Twitter's Violent Threats policy protecting and whose voices are being silenced in turn? Why is it that the burden of marking, reporting, and documenting tweets of violence is disproportionately placed on the recipients, whose complaints are often disregarded or ignored? Alternatively, we might wonder what it would be like to participate in a platform that is serious about accounting for experiences of violence and silencing- siding with those who are being threatened by mitigating violent and intimidating tweets no matter how veiled or ambiguous? Such an approach would entail having regard for power differentials that mark the relational aspect of the speakers and audiences as well as the socio-political, cultural, and historical context of public discourses and public fora. The task of online moderation is not simply one of identifying and removing abusive and hateful speech. It is a societal problem that is fundamental to how individuals and groups experience and practice freedom of expression without fear.

\section{CONCLUSION}

Threat moderation policies on social media platforms present many challenges. Twitter's Violent Threats policy has specifically been criticized by several prominent public figures for its failure to mitigate online toxicity. In this paper, we drew attention to the shortcomings of Twitter's Violent Threats policy by comparing it to the threat assessment frameworks of both linguistic and legal scholars. By showcasing the similarities and differences of these frameworks, we highlighted the importance of incorporating how one may interpret or perceive a tweet as part of Twitter's threat moderation policy (as well as other social media platforms). We also draw upon these frameworks to analyze three specific tweets, which, more broadly, illustrate how content moderation policies in their aim to promote free expression, may in effect work to hinder it. Through this process, we present a case for technology designers and policy makers to approach the problem of content moderation through an interdisciplinary perspective. This research also highlights that much remains to be explored within the realm of content moderation on social media including but not limited to how online toxicity influences public and democratic discourse offline; how language and discourses of violence against women and people of color are echoed and amplified in virtual spaces; and mechanisms that might foster more inclusive online environments.

\section{REFERENCES}

[1] Jessica Guynn. 2018. Trump, Twitter to blame for Cesar Sayoc threats, Rochelle Ritchie says. USA Today. Retrieved February 25, 2021 from https://www.usatoday.com/story/news/2018/10/26/cesar-sayoc-threatsrochelle-ritchie-blames-twitter-trump/1779398002/

[2] Azmina Dhrodia. 2018. Why is Twitter still not acting when it receives reports of death threats? Amnesty International. Retrieved February 25, 2021 from https://www.amnesty.org/en/latest/news/2018/10/why-is-twitter-still-notacting-on-reports-of-death-threats/

[3] Twitter Safety. 2018. An update. We made a mistake when Rochelle Ritchie first alerted us to the threat made against her. The Tweet clearly violated our rules and should have been removed. We are deeply sorry for that error. @TwitterSafety. Retrieved April 27, 2021 from https://twitter.com/TwitterSafety/status/
1055999127446728704

[4] About Twitter $\mid$ Healthy conversations. Retrieved February 25, 2021 from https: //about.twitter.com/en/our-priorities/healthy-conversations.html

[5] 2017. "We found no violation of Twitter's Rules." Medium. Retrieved April 27, 2021 from https://medium.com/@no_violation_of_twitter_rules/abuse-98002aaf35d8

[6] Rebecca Macatee. 2014. Jennifer Lawrence Will Never Join Twitter, Social Media "Because the Internet Has Scorned Me So Much." NECN. Retrieved April 29, 2021 from https://www.necn.com/news/national-international/jenniferlawrence-will-never-join-twitter-social-media-mockingjay/2040829/

[7] Lindy West. 2017. I've left Twitter. It is unusable for anyone but trolls, robots and dictators | Lindy West. the Guardian. Retrieved April 27, 2021 from http://www.theguardian.com/commentisfree/2017/jan/03/ive-left-twitterunusable-anyone-but-trolls-robots-dictators-lindy-west

[8] Hassan Mohamed, Syahaneim Marzukhi, Zuraini Zainol, Tengku Mohd Tengku Sembok, and Omar Zakaria. 2018. Semantic-based Social Media Threats Detection. In Proceedings of the 12th International Conference on Ubiquitous Information Management and Communication (IMCOM '18), Association for Computing Machinery, New York, NY, USA, 1-4. DOI:https://doi.org/10.1145/3164541.3164620

[9] Mainack Mondal, Leandro Araújo Silva, and Fabrício Benevenuto. 2017. A Measurement Study of Hate Speech in Social Media. In Proceedings of the 28th ACM Conference on Hypertext and Social Media (HT '17), Association for Computing Machinery, New York, NY, USA, 85-94. DOI:https://doi.org/10.1145/3078714.3078723

[10] Claire Hardaker and Mark McGlashan. 2016. "Real men don't hate women": Twitter rape threats and group identity. Journal of Pragmatics 91, (January 2016), 80-93. DOI:https://doi.org/10.1016/j.pragma.2015.11.005

[11] Noman Ashraf, Rabia Mustafa, Grigori Sidorov, and Alexander Gelbukh. 2020. Individual vs. Group Violent Threats Classification in Online Discussions. In Companion Proceedings of the Web Conference 2020 (WWW '20), Association for Computing Machinery, New York, NY, USA, 629-633. DOI:https://doi.org/10. $1145 / 3366424.3385778$

[12] Aksel Wester, Lilja Øvrelid, Erik Velldal, and Hugo Hammer. 2016. Threat detection in online discussions. 66-71. DOI:https://doi.org/10.18653/v1/W16-0413

[13] Katie Cohen, Fredrik Johansson, Lisa Kaati, and Jonas Clausen Mork. 2014. Detecting Linguistic Markers for Radical Violence in Social Media. Terrorism and Political Violence 26, 1 (January 2014), 246-256. DOI:https://doi.org/10.1080/09546553.2014. 849948

[14] Reuben Binns, Michael Veale, Max Van Kleek, and Nigel Shadbolt. 2017. Like Trainer, Like Bot? Inheritance of Bias in Algorithmic Content Moderation. In Social Informatics (Lecture Notes in Computer Science), Springer International Publishing, Cham, 405-415. DOI:https://doi.org/10.1007/978-3-319-67256-4 32

[15] Robert Gorwa, Reuben Binns, and Christian Katzenbach. 2020. Algorithmic content moderation: Technical and political challenges in the automation of platform governance. Big Data \& Society 7, 1 (January 2020), 2053951719897945. DOI:https://doi.org/10.1177/2053951719897945

[16] Ana Valens. 2021. Twitter suspended me for making a "slut" joke. But what if I am a slut? The Daily Dot. Retrieved April 27, 2021 from https://www.dailydot. com/irl/twitter-slut-ana-valens/

[17] Sarah Hewitt, T. Tiropanis, and C. Bokhove. 2016. The problem of identifying misogynist language on Twitter (and other online social spaces). In Proceedings of the 8th ACM Conference on Web Science (WebSci '16), Association for Computing Machinery, New York, NY, USA, 333-335. DOI:https://doi.org/10.1145/2908131. 2908183

[18] Toxic Twitter - The Reporting Process. Retrieved February 26, 2021 from https://www.amnesty.org/en/latest/research/2018/03/online-violence-againstwomen-chapter-4/

[19] Bailey Poland. 2016. TYPES OF CYBERSEXISM: What Online Harassment Really Looks Like. In Haters: Harassment, Abuse, and Violence Online. University of Nebraska Press, 35-60. DOI:https://doi.org/10.2307/j.ctt1fq9wdp.4

[20] Desmond Upton Patton, Patrick Leonard, Caitlin Elaesser, Robert D. Eschmann, Sadiq Patel, and Shantel Crosby. 2019. What's a Threat on Social Media? How Black and Latino Chicago Young Men Define and Navigate Threats Online. Youth \& Society 51, 6 (September 2019), 756-772. DOI:https://doi.org/10.1177/ $0044118 X 17720325$

[21] Michael Brice-Saddler. He easily found hundreds of death threats against Rep. Ilhan Omar. He wants Twitter to stop them. Washington Post. Retrieved February 26, 2021 from https:/www.washingtonpost.com/technology/2019/04/16/heeasily-found-hundreds-death-threats-against-rep-ilhan-omar-he-wantstwitter-stop-them/

[22] Donnie O'Sullivan and Alaa Elassar. Twitter bans posts wishing for Trump death. The Squad wonders where that policy was for them. CNN. Retrieved December 6, 2020 from https://www.cnn.com/2020/10/03/politics/twitter-trump-policy-banthe-squad-politics-trnd/index.html

[23] Eva. 2020. Hands up if someone has ever tweeted wishing for you to die or suffer bodily harm. @evacide. Retrieved April 24, 2021 from https://twitter.com/evacide/ status/1312171500087042048

[24] Megan Specia. 2019. Threats and Abuse Prompt Female Lawmakers to Leave U.K. Parliament. The New York Times. Retrieved April 19, 2021 from https://www. nytimes.com/2019/11/01/world/europe/women-parliament-abuse.html 
[25] Sarah Kerr, Ainara Tiefenthäler, and Nicole Fineman. Video: 'Where's Your Husband?' What Female Candidates Hear on the Trail. The New York Times. Retrieved March 22, 2021 from https://www.nytimes.com/video/us/politics/ 100000006027375/women-politics-harassment.html

[26] Sarah Kelly. 2018. Investigating the phonetic and linguistic features used by speakers to communicate an intent to harm. Ph.D. Dissertation. University of York.

[27] Bruce Fraser. 1998. Threatening revisited. Forensic Linguistics-the International Journal of Speech Language and The Law - FORENSIC LINGUIST 5, (December 1998), 159-173. DOI:https://doi.org/10.1558/sll.1998.5.2.159

[28] JL Austin. 1962. How to do things with words. Oxford University Press (1962), 174

[29] Rae Langton. 1993. Speech Acts and Unspeakable Acts. Philosophy \& Public Affairs 22, 4 (1993), 293-330.

[30] Kate Storey. 1995. The language of threats. IfSLL 2, 1 (1995), 74-80. DOI:https: //doi.org/10.1558/ijsll.v2i1.74

[31] Tammy A. Gales. 2010. Ideologies of Violence: A Corpus and Discourse Analytic Approach to Stance in Threatening Communications. Ph.D Dissertation. University of California, Davis.

[32] Tammy Gales. 2015. Threatening Stances: A corpus analysis of realized vs. nonrealized threats. Language and Law 2, (2015), 25.

[33] Mitchell J. Abrams. 2019. Uncovering The Genre Of Threatening Texts: A Multilayered Corpus Study. Master's thesis. Georgetown University, Washington, DC

[34] Holger Limberg. 2008. Threats in Conflict Talk: Impoliteness and Manipulation In Impoliteness in Language: Studies on its Interplay with Power in Theory and Practice, Derek Bousfield, Miriam A. Locher, Ed. 155-179.

[35] Susan Berk-Seligson and Mitchell A. Seligson. 2016. Reported threats: The routinization of violence in Central America. PRAG 26, 4 (December 2016), 583-607. DOI:https://doi.org/10.1075/prag.26.4.03ber

[36] Roger W. Shuy. 1993. Language crimes: The use and abuse of language evidence in the courtroom. Cambridge, MA.

[37] James T. Turner and Michael G. Gelles. 2003. Threat assessment: A risk manage ment approach. Haworth Press, New York, NY

[38] Violent threats policy. Retrieved February 25, 2021 from https://help.twitter.com/ en/rules-and-policies/violent-threats-glorification

[39] Roger W. Shuy. 2005. Creating Language Crimes: How Law Enforcement Uses (and Misuses) Language. Oxford University Press, Cambridge, MA.

[40] What Does Free Speech Mean? United States Courts. Retrieved April 28, 2021 from https://www.uscourts.gov/about-federal-courts/educational-resources/ about-educational-outreach/activity-resources/what-does

[41] David L. Hudson Jr. Watts Factors. The First Amendment Encyclopedia: Presented by the fohn Seigenthaler Chair of Excellence in First Amendment Studies. Retrieved December 26, 2020 from https://www.mtsu.edu/first-amendment/article/1525/ watts-factors

[42] Paul T Crane. "True Threats" and the Issue of Intent. Virginia Law Review 92, 55

[43] Court Role and Structure. United States Courts. Retrieved April 24, 2021 from https://www.uscourts.gov/about-federal-courts/court-role-and-structure

[44] School Shooter. Federal Bureau of Investigation. Retrieved February 25, 202 from https://www.fbi.gov/file-repository/stats-services-publications-schoolshooter-school-shooter/view

[45] Lawrence M. Solan and Peter M. Tiersma. Speaking of Crime: The Language of Criminal Justice. The University of Chicago Press, Chicago
[46] Mary Margaret Roark. 2015. Elonis v. United States: The Doctrine of True Threats: Protecting Our Ever-Shrinking First Amendment Rights in the New Era of Communication. Pittsburgh fournal of Technology Law \& Policy 15, 2 (August 2015), 197-223. DOI:https://doi.org/10.5195/tlp.2015.162

[47] Elonis v. United States, 575 U.S. _ (2015)

[48] Angus Johnston. 2015. Why Today's Elonis Decision is a Victory in the Fight Against Online Harassment. Student Activism. Retrieved November 18, 2020 from https://studentactivism.net/2015/06/01/why-todays-elonis-decision-is-avictory-in-the-fight-against-online-harassment/

[49] John Sivils. 2019. Online Threats: The Dire Need for a Reboot in True-Threats Jurisprudence. SMU L. Rev. F. 72, 1 (November 2019), 51-58. DOI:https://doi.org/ $10.25172 /$ slrf.72.1.5

[50] Grace Panetta and Samantha Lee. 2019. Twitter is the most popular social media platform for members of Congress - but prominent Democrats tweet more often and have larger followings than Republicans. Business Insider. Retrieved April 28, 2021 from https:/www.businessinsider.com/democratic-republican-congresstwitter-followings-political-support-2019-2

[51] Cécile Guerin and Eisha Maharasingam-Shah. 2020. Public Figures, Public Rage: Candidate abuse on social media. ISD: Institute of Strategic Dialogue. Retrieved April 28, 2021 from https://www.isdglobal.org/isd-publications/public-figurespublic-rage-candidate-abuse-on-social-media/

[52] MEET YOUR MAKER (phrase) American English definition and synonyms | Macmillan Dictionary. Retrieved February 26, 2021 from https://www. macmillandictionary.com/us/dictionary/american/meet-your-maker

[53] Examples of Hyperbole: What It Is and How to Use It. Retrieved February 26, 2021 from https://examples.yourdictionary.com/examples-of-hyperboles.html

[54] Ryan Lizza, Daniel Lippman, and Meridith McGraw. AOC wants to cancel those who worked for Trump. Good luck with that, they say. POLITICO. Retrieved February 26, 2021 from https://www.politico.com/news/2020/11/09/aoc-cancelworked-for-trump- 435293

[55] Trump Accountability Project: Meet new group seeking to blacklist staff who worked for Trump administration - World News, Firstpost. Retrieved February 26, 2021 from https://www.firstpost.com/world/trump-accountabilityproject-meet-new-group-seeking-to-blacklist-staff-who-worked-for-trumpadministration-9007641.html

[56] Definition of HUNT. Retrieved February 26, 2021 from https://www.merriamwebster.com/dictionary/hunt

[57] Davey Alba, Kate Conger, and Raymond Zhong. 2020. Twitter Adds Warnings to Trump and White House Tweets, Fueling Tensions. The New York Times. Retrieved April 28, 2021 from https:/www.nytimes.com/2020/05/29/technology/trumptwitter-minneapolis-george-floyd.html

[58] Who Is AOC: Alexandria Ocasio-Cortez on Her Rise to Political Power | Vanity Fair. Retrieved February 26, 2021 from https://www.vanityfair.com/news/2020/ 10/becoming-aoc-cover-story-2020

[59] Breaking the News: Censorship, Suppression, and the 2020 Election | United States Senate Committee on the Judiciary. Retrieved February 26, 2021 from https://www.judiciary.senate.gov/meetings/breaking-the-news-censorshipsuppression-and-the-2020-election

[60] Nassim JafariNaimi, Lisa Nathan, and Ian Hargraves. 2015. Values as Hypotheses: Design, Inquiry, and the Service of Values. Design Issues 31, (October 2015), 91-104. DOI:https://doi.org/10.1162/DESI_a_00354 